\title{
Novel association of the obesity risk-allele near Fas Apoptotic Inhibitory Molecule 2 (FAIM2) gene with heart rate and study of its effects on myocardial infarction in diabetic participants of the PREDIMED trial
}

Dolores Corella ${ }^{1,2,21^{*}}$, Jose V Sorli ${ }^{1,2}$, José I González ${ }^{1,2}$, Carolina Ortega ${ }^{1,2}$, Montserrat Fitó ${ }^{2,3}$, Monica Bulló ${ }^{2,4}$, Miguel Angel Martínez-González ${ }^{2,5}$, Emilio Ros 2,6, Fernando Arós ${ }^{2,7}$, José Lapetra ${ }^{2,8}$, Enrique Gómez-Gracia ${ }^{2,9}$, Lluís Serra-Majem ${ }^{2,10}$, Valentina Ruiz-Gutierrez ${ }^{2,11}$, Miquel Fiol ${ }^{2,12}$, Oscar Coltell ${ }^{2,13}$, Ernest Vinyoles ${ }^{14}$, Xavier Pintó 2,15 , Amelia Martí2,16, Carmen Saiz ${ }^{1}$, José M Ordovás ${ }^{17,18,19}$ and Ramón Estruch ${ }^{2,20}$

\begin{abstract}
Background: The Fas apoptotic pathway has been implicated in type 2 diabetes and cardiovascular disease. Although a polymorphism (rs7138803; G > A) near the Fas apoptotic inhibitory molecule 2 (FAIM2) locus has been related to obesity, its association with other cardiovascular risk factors and disease remains uncertain.

Methods: We analyzed the association between the FAIM2-rs7138803 polymorphism and obesity, blood pressure and heart rate in 7,161 participants (48.3\% with type 2 diabetes) in the PREDIMED study at baseline. We also explored gene-diet interactions with adherence to the Mediterranean diet (MedDiet) and examined the effects of the polymorphism on cardiovascular disease incidence per diabetes status after a median 4.8-year dietary intervention (MedDiet versus control group) follow-up.
\end{abstract}

Results: We replicated the association between the FAIM2-rs7138803 polymorphism and greater obesity risk (OR: 1.08; 95\% Cl: 1.01-1.16; $\mathrm{P}=0.011$; per-A allele). Moreover, we detected novel associations of this polymorphism with higher diastolic blood pressure (DBP) and heart rate at baseline ( $\mathrm{B}=1.07 ; 95 \% \mathrm{Cl}: 0.97-1.28 \mathrm{bmp}$ in $\mathrm{AA}$ vs $\mathrm{G}$-carriers for the whole population), that remained statistically significant even after adjustment for body mass index $(P=0.012)$ and correction for multiple comparisons. This association was greater and statistically significant in type-2 diabetic subjects ( $B=1.44: 95 \% \mathrm{Cl}: 0.23-2.56$ bmp; $P=0.010$ for $A A$ versus $G$-carriers). Likewise, these findings were also observed longitudinally over 5-year follow-up. Nevertheless, we found no statistically significant gene-diet interactions with MedDiet for this trait. On analyzing myocardial infarction risk, we detected a nominally significant $(P=0.041)$ association in type-2 diabetic subjects (HR: 1.86; 95\% Cl:1.03-3.37 for AA versus G-carriers), although this association did not remain statistically significant following correction for multiple comparisons.

(Continued on next page)

\footnotetext{
*Correspondence: dolores.corella@uv.es

1 Department of Preventive Medicine and Public Health, School of Medicine,

University of Valencia, Valencia, Spain

${ }^{2}$ CIBER Fisiopatología de la Obesidad y Nutrición, Instituto de Salud Carlos III,

Madrid, Spain

Full list of author information is available at the end of the article
} 


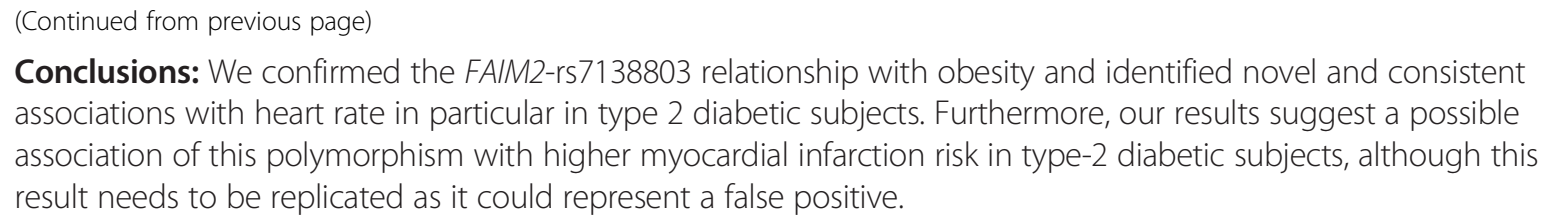

Keywords: Heart rate, FAIM2, Apoptosis

\section{Background}

Obesity is a major determinant of type 2 diabetes. Over the last decade, multiple genome wide association studies (GWAs) have identified numerous polymorphisms associated with body mass index (BMI), and some of them have also been related to higher type 2 diabetes risk [1-7]. However, how the majority of these genes function in affecting anthropometric-related parameters is unknown. Moreover, both obesity and type 2 diabetes have been associated with higher blood pressure and cardiovascular disease risk $[8,9]$. Currently, to better understand the possible mechanisms involved, some studies have also analyzed the association between these obesity-related genes with cardiovascular risk factors such as hypertension, metabolic syndrome, etc. [10-13]. The FAIM2 (Fas apoptotic inhibitory molecule 2) is one of the less well-known genes associated with obesity. The rs7138803 (G > A) single nucleotide polymorphism (SNP) located near the FAIM2 locus was described for the first time to be associated with higher BMI in carriers of the minor allele by Thorleifsson et al. [4]. Later, Speliotes et al. [6] in a larger GWAs confirmed this association and estimated that the increase of BMI per variant allele would be $\sim 0.12 \mathrm{~kg} / \mathrm{m}^{2}$. However, the results of later studies in different populations have been diverse [14-20], suggesting some heterogeneity of the association depending on the characteristics of the population analyzed. FAIM2, also called NMP35 (neural membrane protein 35 ), or $L F G$ (lifeguard), is known to codify for an antiapoptotic protein, highly expressed in the brain that antagonizes the Fas pathway [21,22]. Fas (CD95 or APO1 ) is a cell surface receptor, expressed in a variety of tissues. FasL is a member of the tumour necrosis factor superfamily and the natural ligand to Fas [23]. Various studies have associated both Fas and FasL concentrations with hypertension and cardiovascular risk [24,25], and there is a study in Chinese subjects showing an association between the FAIM2-rs7138803 polymorphism and diastolic blood pressure [26]. However, there are no published studies in humans that have analyzed the association between the FAIM2-rs7138803 polymorphism and resting heart rate, which is an independent and important risk factor of cardiovascular diseases [27-29], mainly in type 2 diabetic patients [30]. Although, in animal models, it has been shown that Faim2 is a novel neuroprotective molecule in the context of cerebral ischemia [31], there are no studies on humans that have analyzed the association between FAIM2 polymorphisms and cerebrovascular disease risk. Only one previous study, carried out in a Chinese population [32], has examined the association between the FAIM2-rs7138803 polymorphism and cardiovascular disease, but no statistical association was found. Taking into account that the Fas apoptotic pathway has been implicated in type 2 diabetes and that a high glucose intake can induce vascular endothelial cell apoptosis and higher risk of myocardial infarction [33,34], we hypothesized that the association between the FAIM2-rs7138803 polymorphism and heart rate and cardiovascular disease would be greater in type 2 diabetic subjects. Additionally, diet may modulate this association, as one experimental study showing that nutritional state affects the expression of the Faim2 gene suggested [35]. Thus, our aims were: 1) To analyze the association of the FAIM2-rs7138803 polymorphism with anthropometrical measures, blood pressure and resting heart rate in the whole population and in type 2 diabetic subjects at baseline, also analyzing its modulation by adherence to the MedDiet; 2) To study the longitudinal association of the polymorphism with heart rate and with incidence of cardiovascular diseases (stroke and myocardial infarction) by diabetes status, also analyzing modulation by intervention with MedDiet.

\section{Methods}

\section{Subjects}

We analyzed 7,161 participants (3,049 men and 4,112 women) in the PREDIMED (PREvención con DIeta MEDiterránea) trial from whom the FAIM2-rs7138803 polymorphism was successfully determined. The PREDIMED study is a multi-center, randomized, controlled clinical trial (controlled-trials.com number, ISRCTN35739639) aimed at assessing the effects of the MedDiet on the primary prevention of cardiovascular disease [36]. The completion date of this study was December 2010 and the total number of randomized subjects was 7,447. The 7,161 participants included in the present study did not differ in the main characteristics from those of the total cohort. Additional file 1: Figure S1 shows the CONSORT flowchart of the trial. 
Details of the PREDIMED trial including sample size calculations and interim analysis have been fully described elsewhere [36-38]. Briefly, from October 2003 physicians in Primary Care Centers selected high cardiovascular risk subjects. Eligible subjects were community-dwelling people (55-80 years of age for men; $60-80$ years of age for women) who fulfilled at least one of two criteria: type 2 diabetes [39] or three or more cardiovascular risk factors as previously detailed [36-38]. Exclusion criteria included a personal history of cardiovascular disease, any severe chronic illness, and drug or alcohol addiction [36]. Participants were randomly assigned to three interventions: MedDiet with extra-virgin olive oil, MedDiet with mixed nuts and control group (low-fat diet). Participants assigned to both MedDiet groups received intensive training to follow the MedDiet and allocations of either extra virgin olive oil (1 litre/week, for all the family) or mixed nuts $(30 \mathrm{~g} / \mathrm{d})$ at no cost $[36,37]$. Participants assigned to the control diet received recommendations on reducing the intake of all types of fat. A detailed description of the nutritional interventions has been provided elsewhere [36]. The Institutional Review Board/Ethics Committee of each participating center approved the study protocol. All participants provided written informed consent. Participants were followed up for a median of 4.8 years (interquartile range, 2.8 to 5.8 years). Data were analyzed cross-sectionally (at baseline) as well as longitudinally (pooling together the MedDiet intervention groups versus the control group). By December 2010, a total of 502 participants (7.0\%) had been lost to follow-up for 2 or more years. Dropout rates were higher in the control group (11\%) than in the MedDiet groups (5\%) (Additional file 1: Figure S1). As compared with participants who remained in the trial, those who dropped out were younger (by 1.4 years), had a higher BMI and a lower score for the adherence to the MedDiet as previously detailed elsewhere [36]. The effect of the FAIM2-rs7138803 polymorphism on heart rate was also examined longitudinally analyzing all subjects having heart rate data at baseline, at 1 -year, at 3 -years and at 5 -years $(\mathrm{n}=2,310)$. The reduction in the number of cases in the longitudinal analysis was mainly due no to patients being lost during follow up, but to the fact that patients were not all recruited in the same year at the beginning of the study, but progressively over the following years (from 2003 to 2009) as previously described [36]. Therefore, individuals who entered the study in 2003 completed the 5-year follow-up period in the year 2010, which is when follow-up ended, whereas those who entered the study in later years could not complete the 5-year follow-up period and so were not included in the longitudinal analyses of the study on heart rate. The Institutional Review Board/Ethics Committee of each participating center approved the study protocol. All participants provided written informed consent.

\section{Demographic, clinical, anthropometric and dietary measurements}

The baseline examination included an assessment of standard cardiovascular risk factors, medication use, socio-demographic factors and lifestyle variables, as previously detailed [36,38]. Food consumption was determined by a validated semi-quantitative food frequency questionnaire [40]. Adherence to MedDiet at baseline was assessed by a validated 14-item questionnaire [41]. The final score ranged from 0 to 14 . The greater the score obtained from the questionnaire, the greater the adherence to the MedDiet. Physical activity was estimated by the Minnesota Leisure-Time Physical Activity Questionnaire, as previously described [36].

Weight and height were measured with calibrated scales and a wall-mounted stadiometer, respectively. BMI was calculated as weight in kilograms divided by the square of height in meters.

At baseline and yearly thereafter, trained personnel measured blood pressure and heart rate in triplicate using a validated semiautomatic oscillometer (Omron HEM-705CP, Hoofddorp, the Netherlands) with a 5-minute interval between each measurement with the patients seated and at rest in a peaceful setting. The means of these measurements were calculated.

\section{Outcome ascertainment}

The primary endpoint was the occurrence of the first major cardiovascular events and comprised myocardial infarction, stroke or cardiovascular death [36]. We used four sources of information to identify end-points: 1) repeated contacts with participants; 2) family physicians; 3) yearly review of medical records; and 4) consultation of the National Death Index. The end-point adjudication committee, whose members were blind to treatment allocation, examined all medical records related to endpoints. Only end-points confirmed by the adjudication committee that occurred between October 1, 2003, and December 1, 2010 were included in the analyses. The criteria for adjudicating primary outcomes are detailed elsewhere [36].

\section{Biochemical determinations, DNA extraction and genotyping}

At baseline, blood samples were obtained from each participant after an overnight fast and were frozen at $-80^{\circ} \mathrm{C}$. Fasting glucose, total cholesterol, triglycerides, HDL-C and LDL-C were measured using standard methods as previously described [37].

Genomic DNA was extracted from buffy-coat with the MagNaPure LC DNA Isolation Kit (Roche Diagnostics, Mannheim, Germany). The rs7138803 (G > A) polymorphism near FAIM2 was genotyped on a 7900HT Sequence Detection System (Applied Biosystems, FosterCity, CA, 
USA) using a fluorescent allelic discrimination $\operatorname{TaqMan}^{\text {Tx }}$ assay. The calling rate was $98 \%$. Genotype frequencies did not deviate from Hardy-Weinberg equilibrium expectations $(\mathrm{P}=0.378)$.

\section{Statistical analyses}

Data were analyzed both at baseline and longitudinally in the intervention trial. Chi-square tests were used to test differences in percentages. $T$ and ANOVA tests were applied to compare crude means of continuous variables among genotypes at baseline. Multivariable adjustments for continuous variables were carried out by linear regression analysis and regression coefficients (B) were estimated. Models were sequentially adjusted for age, sex, center, type 2 diabetes, total energy intake, adherence to MedDiet, alcohol, tobacco, physical activity, hypertension, and medications (antihypertensive, lipid-lowering and hypoglycemic drugs) as indicated. Antihypertensive medication included angiotensin-converting enzymes (ACE) inhibitors (48\% of the population took these), diuretics (21\% of the population) and other antihypertensive drugs (beta blockers, calcium channel blockers, etc.) regardless of the dosage, as previously described [36]. Three dummy variables (taking or not taking the corresponding drug regardless of the dosage) were considered for the antihypertensive medication including ACE inhibitors, diuretics and other antihypertensive drugs. In addition a dummy variable (taking or not taking) for lipid-lowering drugs and two dummy variables (one for insulin and other for oral antidiabetic agents) were included in the adjustment for medications. Hypertension was defined as systolic blood pressure $>=140 \mathrm{~mm} \mathrm{Hg}$ or diastolic blood pressure $>=90 \mathrm{mmHg}$ or under antihypertensive medication. The FAIM2-rs7138803 polymorphism was first tested as additive for continuous traits analyzed. However, when the differences between heterozygous and homozygous subjects for the variant A-allele were very small, a recessive model was selected (for heart rate). A dichotomous variable for the prerandomization adherence to MedDiet was created using the sample means as cut-off values ( 9 points). Obesity was defined as BMI $>=30 \mathrm{~kg} / \mathrm{m}^{2}$. Logistic regression methods were also used to estimate the contribution of the FAIM2-rs7138803 polymorphism to predict obesity. In addition, BMI was categorized into four categories $\left(\mathrm{BMI}<25 \mathrm{~kg} / \mathrm{m}^{2} ; 25-30 \mathrm{~kg} / \mathrm{m}^{2} ; 30-35 \mathrm{~kg} / \mathrm{m}^{2}\right.$ and $>=35 \mathrm{~kg} / \mathrm{m}^{2}$ ). Heart rate in beats per minute (bmp) was also categorized into five categories $(<=60,60-70$, $70-80,80-90$ and $>=90 \mathrm{bmp}$ ) for categorical analyses. The interaction between the FAIM2-rs7138803 polymorphism and adherence to the MedDiet in determining BMI, blood pressure and resting heart rate at baseline was tested in multivariable regression models (linear or logistic for categorical) including the corresponding main effects and interaction terms. Subgroup analyses stratified by type 2 diabetes status were carried out according to our "a priori" hypothesis and aim. The effect of the FAIM2-rs7138803 polymorphism on heart rate in the whole population and stratified by type 2 diabetes status was also examined longitudinally analyzing all subjects having heart rate data at baseline, at 1-year, at 3 -years and at 5-years $(\mathrm{n}=2,310)$ in a multivariable model of repeated measures with interactions terms after adjustment for the dietary intervention and the indicated covariates. Dietary intervention was considered as a dichotomous variable pooling together the MedDiet intervention groups versus the control group after having checked the homogeneity of the effect in the two MedDiet groups). In addition, we analyzed the interaction term between the FAIM2-rs7138803 and dietary intervention on changes in heart rate at 5-years by linear regression analysis with multivariable adjustment. Finally, we examined the association between the FAIM2-rs7138803 polymorphism and cardiovascular events (total cardiovascular events, myocardial infarction or stroke) in the whole population and in type 2 diabetic subjects by Cox regression models with the length of follow-up as the primary time variable and adjustment for the dietary intervention and the other covariates as indicated. The exposure time was calculated as the time between randomization and the date of a major cardiovascular event, the date when completing the last interview, December 1st 2010, or the date at death, whichever came first. Hazard ratios (HR) with 95\% confidence intervals (CI) for the FAIM2-rs7138803 polymorphism (recessive model) for cardiovascular diseases were calculated in the population as a whole. In addition, we carried out the stratified analysis by type- 2 diabetes status. Analyses were based on the intention-to-treat principle. In multivariable model 1 we adjusted for sex, age, center and dietary intervention. Multivariable model 2 included additional adjustments for BMI, total energy intake, alcohol, smoking, type-2 diabetes, medications and physical activity. Additional adjustments for baseline hypertension were also undertaken. The proportionality of hazards in determining the main outcomes in the PREDIMED study was tested with the use of time-varying covariates as previously described [36]. Here we graphically checked the assumption of proportional hazards for the genetic factor (FAIM2) by looking at the Log-Log plot of survival. We obtained parallel lines for the curves of genotypes in all the models fitted. Finally, Kaplan-Meier survival curves were plotted to estimate the probability of remaining free of myocardial infarction during follow-up. Statistical analyses were performed with the SPSS package, version 18.0 (SPSS, Chicago, IL). All tests were two-tailed and the nominal significance level was set at a P-value $<0.05$. In addition, the Bonferroni 
correction was applied to compensate for multiple comparisons. Our approach consisted of using an adjusted alpha level equal to the nominal alpha level (0.05), divided by the number of new hypothesis tested. With the aim of achieving a balance between type I and type II errors, we have chosen to undertake the Bonferroni correction considering the three new groups of variables that we were investigating (heart rate, blood pressure and cardiovascular diseases). Anthropometric measures were not included in the correction because in this case we were not dealing with a new hypothesis of association. Thus, the adjusted alpha was $0.05 / 3=0.017$. The significance of each original (uncorrected) test was assessed at this level. Thus, a P-value $<0.017$ was considered to be statistically significant taking into account the correction for multiple comparisons.

\section{Results}

Prevalence of the FAIM2-rs7138803 (G > A) genotypes was: $42.2 \%$ GG, $44.9 \% \mathrm{GA}$ and $12.3 \%$ AA. Table 1 shows demographic, clinical, lifestyle and genetic characteristics of the 7,161 participants in the PREDIMED study according to the randomly assigned dietary intervention groups at baseline. We did not find statistically significant differences on analyzing demographic, lifestyle (dietary intake, smoking, drinking and physical activity), clinical (prevalence of type 2 diabetes, hypertension and medications) or biochemical parameters at baseline among the FAIM2-rs7138803 (Additional file 1: Table S1).

\section{Association between the FAIM2-rs7138803 polymorphism} anthropometrical variables, blood pressure and heart rate at baseline

We observed a statistically significant association between the FAIM2-rs7138803 polymorphism and BMI $\left(B_{\text {adjusted }}=0.15: 95 \%\right.$ CI: $0.02-0.27 \mathrm{~kg} / \mathrm{m}^{2}$ per variantallele; $\mathrm{P}=0.023$ ) in the additive model after adjustment for sex, age, centre, type 2 diabetes, hypertension and medications (Table 2). We also found additive effects in

Table 1 Demographic, clinical, lifestyle and genetic characteristics of the study participants at baseline by intervention groups

\begin{tabular}{|c|c|c|c|c|c|c|c|c|}
\hline \multirow[b]{3}{*}{ Age (years) } & \multirow{2}{*}{\multicolumn{2}{|c|}{$\begin{array}{c}\text { Total } \\
(n=7,161)\end{array}$}} & \multirow{2}{*}{\multicolumn{2}{|c|}{$\begin{array}{c}\text { MedDiet with EVOO } \\
(n=2,469)\end{array}$}} & \multirow{2}{*}{\multicolumn{2}{|c|}{$\begin{array}{c}\text { MedDiet nuts } \\
(n=2,363)\end{array}$}} & \multirow{2}{*}{\multicolumn{2}{|c|}{$\begin{array}{c}\text { Control group } \\
(n=2,329)\end{array}$}} \\
\hline & & & & & & & & \\
\hline & 67.0 & \pm 6.2 & 67.0 & \pm 6.2 & 66.7 & \pm 6.1 & 67.3 & \pm 6.3 \\
\hline $\mathrm{BMI}\left(\mathrm{Kg} / \mathrm{m}^{2}\right)$ & 30.0 & \pm 3.8 & 29.9 & \pm 3.7 & 29.7 & \pm 3.8 & 30.2 & \pm 4.0 \\
\hline Waist circumference $(\mathrm{cm})$ & 100.4 & \pm 10.6 & 100.2 & \pm 10.4 & 100.2 & \pm 10.5 & 100.8 & \pm 10.8 \\
\hline Female sex: $n, \%$ & 4112 & $(57.4)$ & 1448 & $(58.6)$ & 1271 & $(53.8)$ & 1393 & $(59.8)$ \\
\hline Systolic blood pressure $(\mathrm{mmHg})$ & 149.4 & \pm 20.8 & 148.5 & \pm 20.8 & 149.6 & \pm 20.4 & 150.1 & \pm 21.1 \\
\hline Diastolic blood pressure (mmHg) & 83.4 & \pm 11.0 & 83.1 & \pm 10.9 & 83.7 & \pm 10.9 & 83.3 & \pm 11.1 \\
\hline Heart rate (bpm) & 71.4 & \pm 11.2 & 71.4 & \pm 11.1 & 71.2 & \pm 11.1 & 71.6 & \pm 11.3 \\
\hline Current smokers: n,\% & 1003 & $(14.0)$ & 345 & $(14.0)$ & 339 & $(14.3)$ & 319 & (13.7) \\
\hline Type 2 diabetes: n,\% & 3462 & $(48.3)$ & 1238 & $(50.1)$ & 1096 & $(46.8)$ & 1128 & $(48.4)$ \\
\hline Hypertension: n,\% & 5928 & $(82.8)$ & 2026 & $(82.1)$ & 1954 & $(82.7)$ & 1948 & (83.6) \\
\hline Dyslipidemia: n,\% & 5172 & $(72.2)$ & 1766 & $(71.5)$ & 1730 & $(73.2)$ & 1676 & $(72.0)$ \\
\hline \multicolumn{9}{|l|}{ FAIM2-rs7138803 (G > A) : n,\% } \\
\hline GG & 3019 & $(42.2)$ & 1022 & $(41.4)$ & 1000 & $(42.3)$ & 997 & $(42.8)$ \\
\hline GA & 3235 & $(45.2)$ & 1132 & $(45.8)$ & 1062 & $(44.9)$ & 1041 & $(44.7)$ \\
\hline AA & 907 & $(12.7)$ & 315 & $(12.8)$ & 301 & $(12.7)$ & 291 & $(12.5)$ \\
\hline Energy intake (kcal/d) & 2274 & \pm 606 & 2286 & \pm 606 & 2317 & \pm 610 & 2219 & \pm 598 \\
\hline Total fat (\% energy) & 39.2 & \pm 6.8 & 39.3 & \pm 6.9 & 39.4 & \pm 6.5 & 39.0 & \pm 6.8 \\
\hline Saturated fat (\% energy) & 10.0 & \pm 2.3 & 10.0 & \pm 2.2 & 10.0 & \pm 2.2 & 10.0 & \pm 2.3 \\
\hline MUFA (\% energy) & 19.5 & \pm 4.6 & 19.6 & \pm 4.6 & 19.5 & \pm 4.3 & 19.3 & \pm 4.7 \\
\hline Proteins (\% energy) & 16.6 & \pm 2.8 & 16.6 & \pm 2.9 & 16.5 & \pm 2.7 & 16.6 & \pm 2.8 \\
\hline Carbohydrates (\% energy) & 41.9 & \pm 7.1 & 41.7 & \pm 7.2 & 41.5 & \pm 7.0 & 42.3 & \pm 7.2 \\
\hline Adherence to the MedDiet & 8.6 & \pm 2.0 & 8.7 & \pm 2.0 & 8.7 & \pm 2.0 & 8.4 & \pm 2.1 \\
\hline Alcohol consumption (g/d) & 8.4 & \pm 14.2 & 8.6 & \pm 14.4 & 9.2 & \pm 15.0 & 7.5 & \pm 13.1 \\
\hline Physical activity (MET-min/day) & 231 & \pm 239 & 232 & \pm 231 & 247 & \pm 246 & 215 & \pm 241 \\
\hline
\end{tabular}

Values are mean \pm SD for continuous variables and number (\%) for categorical variables. BMI indicates body mass index. MUFA, Monounsaturated fatty acids; MedDiet, Mediterranean diet; EVOO, extra virgin olive oil. 
Table 2 Association between the FAIM2-rs7138803 and anthropometrical measures, blood pressure and heart rate

\begin{tabular}{|c|c|c|c|c|c|c|c|c|c|c|c|c|c|c|}
\hline & & & \multicolumn{12}{|c|}{ FAIM2 (G > A) genotypes } \\
\hline & \multicolumn{2}{|c|}{ GG $(n=3,019)$} & \multicolumn{2}{|c|}{$\mathrm{GA}(n=3,235)$} & \multicolumn{2}{|c|}{ AA $(n=907)$} & \multicolumn{2}{|c|}{ Additive model } & \multirow[b]{2}{*}{$\mathrm{P}^{2}$} & \multirow[b]{2}{*}{$P^{3}$} & \multicolumn{4}{|c|}{ Recessive model } \\
\hline & Mean & SD & Mean & SD & Mean & SD & $P^{1}$ & $\mathrm{~B}^{1}(95 \% \mathrm{Cl})$ & & & $\mathrm{B}^{1}(95 \% \mathrm{Cl})$ & $P^{1}$ & $\mathrm{P}^{2}$ & $P^{3}$ \\
\hline Weight (kg) & 76.4 & \pm 11.9 & 76.9 & \pm 11.9 & 77.3 & \pm 12.1 & 0.026 & $0.46(0.06-0.87)$ & 0.059 & & $0.59(-0.24-1.42)$ & 0.164 & 0.191 & \\
\hline BMI (kg/m2) & 29.9 & \pm 3.8 & 30.0 & \pm 3.9 & 30.1 & \pm 3.9 & 0.055 & $0.13(-0.01-0.26)$ & 0.023 & & $0.20(-0.07-0.47)$ & 0.147 & 0.066 & \\
\hline Waist circumference $(\mathrm{cm})$ & 100.3 & \pm 10.5 & 100.3 & \pm 10.6 & 101.0 & \pm 10.9 & 0.167 & $0.26(-0.11-0.62)$ & 0.141 & & $0.68(-0.07-1.42)$ & 0.075 & 0.085 & \\
\hline $\mathrm{SBP}(\mathrm{mmHg})$ & 149.2 & \pm 20.8 & 149.4 & \pm 20.9 & 149.9 & \pm 20.1 & 0.414 & $0.30(-0.42-1.01)$ & 0.783 & 0.889 & $0.57(-0.89-2.03)$ & 0.443 & 0.761 & 0.896 \\
\hline $\mathrm{DBP}(\mathrm{mmHg})$ & 82.9 & \pm 10.9 & 83.4 & \pm 10.9 & 84.3 & \pm 11.2 & 0.001 & $0.61(0.24-1.00)$ & 0.006 & 0.015 & $1.12(0.36-1.89)$ & 0.004 & 0.009 & 0.017 \\
\hline Heart rate (bpm) & 71.1 & \pm 11.2 & 71.2 & \pm 10.9 & 72.3 & \pm 11.4 & 0.029 & $0.43(0.04-0.81)$ & 0.039 & 0.048 & $1.07(0.29-1.86)$ & 0.007 & 0.010 & 0.012 \\
\hline $\begin{array}{l}\text { Prevalence of } \\
\text { obesity (\%) }\end{array}$ & \multicolumn{2}{|c|}{45.2} & \multicolumn{2}{|c|}{47.5} & \multicolumn{2}{|c|}{49.1} & 0.021 & & & & & 0.136 & & \\
\hline $\begin{array}{l}\text { Obesity risk, } \\
\text { OR ( } 95 \% \text { Cl) }\end{array}$ & \multicolumn{2}{|c|}{1 (ref.) } & \multicolumn{2}{|c|}{$1.10(0.99-1.21)$} & \multicolumn{2}{|c|}{$1.17(1.01-1.35)$} & 0.021 & $1.08(1.01-1.16)$ & 0.011 & & $1.11(0.97-1.28)$ & 0.136 & 0.070 & \\
\hline
\end{tabular}

Means, prevalence, odds ratios (OR), and regression coefficients (B).

Values are means and standard deviations (SD), odds ratio (OR) and $95 \%$ confidence intervals (CI) or regression coefficients (B) and $95 \% \mathrm{Cl}$

B: Regression coefficient per-variant allele effects in the additive model (genotypes coded as 0,1 and 2 according to the number of minor alleles for additive effects) and regression coefficients for homozygotes for

the variant allele versus the other genotypes in the recessive model (genotypes coded as 0 for GG and GA and 1 for $A A$ ).

SBP: Systolic blood pressure. DBP: Diastolic blood pressure.

SBP: Systolic blood pressure. DBP: Diastolic blood pressure.

: : Mnadjusted $\mathrm{P}$ values for the polymorphism for the comparison of means or $\mathrm{OR}$ (in an additive or recessive models as indicated).

: Model 2 additionally adjusted for BMI. Further adjustment for total energy intake, adherence to Mediterranean diet and physical activity did not change the statistical significance of these associations. 
the association of this polymorphism with obesity (OR adjusted: 1.08 ; 95\% CI: $1.01-1.17$ per variant-allele; P: 0.011). Likewise, we obtained a statistically significant association with diastolic blood pressure (DBP) in the additive model adjusted for covariates that remained significant after $\mathrm{BMI}$ adjustment $(\mathrm{P}=0.015)$. Moreover, we observed a novel association between this polymorphism and resting heart rate which was greater in the recessive model, and that remained statistically significant after multivariable adjustment including BMI $(\mathrm{P}=0.012)$. Additional adjustment of the model for DBP did not attenuate the statistical significance of this association $(P=0.010)$. All these association were statistically significant not only at the nominal $\mathrm{P}$-value $(\mathrm{P}<0.05)$ but also after correction for multiple comparisons taking the level of $\mathrm{P}<0.017$ into account.

In the stratified analysis by type- 2 diabetes status (48\% diabetic patients), we observed that the association of the polymorphism with heart rate was greater and statistically significant $(P=0.010)$ in type- 2 diabetic subjects $\left(\mathrm{B}_{\text {adjusted }}=1.44: 95 \% \mathrm{CI}: 0.23-2.56 \mathrm{bmp}\right.$ for $\mathrm{AA}$ versus carriers of the G-allele). No significant association was found in non-diabetics ( $B_{\text {adjusted: }}$ 0.62: $95 \% \mathrm{CI}$ : $0.47-1.69$ bmp; $\mathrm{P}=0.258$, in non-diabetics for AA versus G-carriers). However, in terms of BMI, we found no heterogeneity of the effects of the polymorphism by diabetes status, obtaining similar associations in type 2 diabetic subjects as in non-diabetics (not shown).

We also analyzed (Additional file 1: Table S2) the association of the FAIM2-rs7138803 polymorphism with different categories of BMI and observed that the association increased with BMI categories (P-for trend: 0.008). Categorizing heart rate (Table 3 ) into five categories ( $<=60,60-70,70-80,80-90$ and $>=90 \mathrm{bpm})$, we also observed that the association with the polymorphism was greater as the heart rate category increased (P-for linear trend: 0.002). Thus, prevalence of AA homozygotes was $9.9 \%$ in subjects having a heart rate $<=60 \mathrm{bpm}$, whereas its prevalence was $15.0 \%$ among subjects having a heart rate $>=90 \mathrm{bpm}\left(\mathrm{OR}_{\text {adjusted: }} 1.66\right.$, 95\% CI: 1.13-2.43; $\mathrm{P}=0.009$ for AA homozygotes versus G-allele carriers) in the multivariable adjusted model including BMI.

\section{Modulation by adherence to the MedDiet at baseline of the associations between the FAIM2-rs7138803 polymorphism and anthropometrical variables, DBP and heart rate}

We did not observe any statistically significant gene-diet interaction in the multivariable adjusted models (by sex, age, centre, type 2 diabetes, medications, hypertension, smoking, drinking, physical activity and total energy intake) between adherence to the MedDiet (two categories based on the population mean of 9 points) at baseline and the FAIM2-rs7138803 polymorphism in determining BMI (P-interaction: 0.716) (Additional file 1: Figure S2A), waist circumference (P-interaction: 0.658), obesity $(\mathrm{P}$-interaction $=0.679)$, DBP (P-interaction: 0.346$)$ or heart rate (P-interaction: 0.371) (Additional file 1: Figure S2B).

\section{Stratified analysis per hypertension of the association between the FAIM2-rs7138803 polymorphism and DBP and heart rate}

Although in this study, prevalence of diagnosed hypertension at baseline was very high $(82.8 \%)$, we analyzed whether the association of the polymorphism with DBP (Additional file 1: Figure S3A) and heart rate (Additional file 1: Figure S3B) differed by hypertension status. We obtained no statistically significant interactions and observed homogeneous results across the strata. Statistically significant differences for the polymorphism were detected in subjects with hypertension because this group had a higher sample size.

Table 3 Association between the FAIM2-rs7138803 polymorphism and categories of heart rate

\begin{tabular}{|c|c|c|c|c|c|c|c|c|}
\hline \multirow[b]{2}{*}{ Heart rate } & \multicolumn{2}{|c|}{ FAIM2 $(\mathrm{G}>\mathrm{A})$ genotypes } & \multirow{2}{*}{$\begin{array}{l}\text { Unadjusted }^{1} \\
\text { OR* }^{*}(95 \% \mathrm{Cl})\end{array}$} & \multirow[b]{2}{*}{$P^{1}$} & \multirow{2}{*}{$\begin{array}{c}\text { Adjusted }^{2} \\
\text { OR }^{*}(95 \% \mathrm{Cl})\end{array}$} & \multicolumn{3}{|c|}{ Adjusted $^{3}$} \\
\hline & $G G+G A(n=6,049)$ & $A A(n=888)$ & & & & $\mathrm{P}^{2}$ & $O R^{*}(95 \% \mathrm{Cl})$ & $P^{3}$ \\
\hline$<60$ bpm (\%) & 90.1 & 9.9 & 1 (ref) & & 1 (ref) & & 1 (ref) & \\
\hline 60-70 bmp (\%) & 87.3 & 12.7 & $1.32(1.05-1.67)$ & 0.019 & $1.27(1.00-1.60)$ & 0.051 & $1.26(1.00-1.60)$ & 0.052 \\
\hline 70-80 bmp (\%) & 86.4 & 13.6 & $1.43(1.13-1.82)$ & 0.003 & $1.46(1.14-1.87)$ & 0.003 & $1.45(1.13-1.86)$ & 0.003 \\
\hline $80-90 \mathrm{bmp}(\%)$ & 86.1 & 13.9 & $1.46(1.12-1.92)$ & 0.006 & $1.47(1.10-1.97)$ & 0.009 & $1.46(1.10-1.96)$ & 0.011 \\
\hline$>=90 \mathrm{bmp}(\%)$ & 85.0 & 15.0 & $1.60(1.13-2.27)$ & 0.008 & $1.65(1.13-2.42)$ & 0.010 & $1.66(1.13-2.43)$ & 0.009 \\
\hline$P$ for trend* & 0.002 & & & & & & & \\
\hline
\end{tabular}

Prevalence and odds ratios (OR). Unadjusted and adjusted models.

Values are prevalences in $\%$, odds ratio (OR) and $95 \%$ confidence intervals $(\mathrm{Cl})$.

OR: Odds ratio for the corresponding category of heart rate in comparison with the reference category $(<60$ bpm) for homozygous subjects for the variant allele (recessive model) in comparison with carriers of the major allele.

*: P-value of the $\mathrm{Chi}^{2}$ test for linear trend.

1: Unadjusted $\mathrm{P}$ values for the polymorphism (recessive model).

2: Models adjusted for sex, age, center, type 2 diabetes, hypertension, physical activity, medications, smoking, drinking, adherence to Mediterranean diet and total energy intake.

3: Model 2 additionally adjusted for BMI. 
Longitudinal association between the FAIM2-rs7138803 polymorphism and heart rate

Given that that heart rate was the parameter in which we found the most novel association, we wanted to study whether the association between the FAIM2-rs7138803 polymorphism and heart rate was maintained over time and how the intervention with MedDiet (MedDiet groups vs control group after having observed no heterogeneity in the MedDiet groups) influenced that association. We used longitudinal data from 5-year follow-up analyzing data for all subjects having heart rate measured at baseline, at 1-year, at 3-years and at 5years $(n=2,310)$ in a model for repeated measures. Prevalence of the FAIM2-rs7138803 genotypes in this group was 41.3\% GG, $44.8 \%$ GA and $13.9 \%$ AA, very close to the population as a whole. The mean age was the same $(67.1 \pm$ 6.0 years) as in the population as a whole. There were slight differences in other demographic or clinical variables. Thus, in this group prevalence of women was $56.4 \%$, prevalence of type 2 diabetes was $45.1 \%$, mean BMI was $29.7 \pm 3.6 \mathrm{~kg} / \mathrm{m}^{2}$, mean SBP was $84.4 \pm 10.8 \mathrm{mmHg}$ and mean heart rate was $70.5 \pm 10.8 \mathrm{bpm}$.

Having firstly tested an additive model and observed similar effects in heterozygous and in homozygous subjects, we employed the recessive model. For the whole population, we detected a statistically significant effect of the polymorphism in determining the heart rate over the 5-year follow-up period ( $\mathrm{P}=0.004$ in the model adjusted for intervention with MedDiet, sex, age, centre, baseline BMI, type 2 diabetes, hypertension, medications, smoking and physical activity). We did not obtain a significant interaction between the FAIM2-rs7138803 polymorphism and intervention with MedDiet in the follow-up for the whole population (P-interaction: 0.392, in the adjusted model). Neither did we obtain significant interactions between these variables in determining changes in heart rate $(\mathrm{P}=0.215)$.

In the analysis stratified by diabetes status ( $\mathrm{n}=1,076$ subjects with type- 2 diabetes and $n=1,234$ non-diabetics), we found that the longitudinal association between the FAIM2-rs7138803 polymorphism and heart rate was higher and statistically significant in subjects with type- 2 diabetes $(\mathrm{P}=0.002$ for the polymorphism in the longitudinal analysis of the multivariable adjusted model) (Figure 1). This longitudinal association remained statistically significant after correction for multiple comparisons. No statistically significant association for the polymorphism in the follow-up was detected in non-diabetics $(P=0.135)$. Even in type 2 diabetic subjects we did not detect a significant interaction between the polymorphism and the intervention with MedDiet (P-interaction $=0.587$, multivariable adjusted) in the follow-up.

\section{Association between FAIM2-rs7138803 polymorphism and incidence of cardiovascular events and mortality after 4.8-years follow-up}

After a median follow-up of 4.8 years (interquartile range, 2.8 to 5.8 years), 268 major cardiovascular events

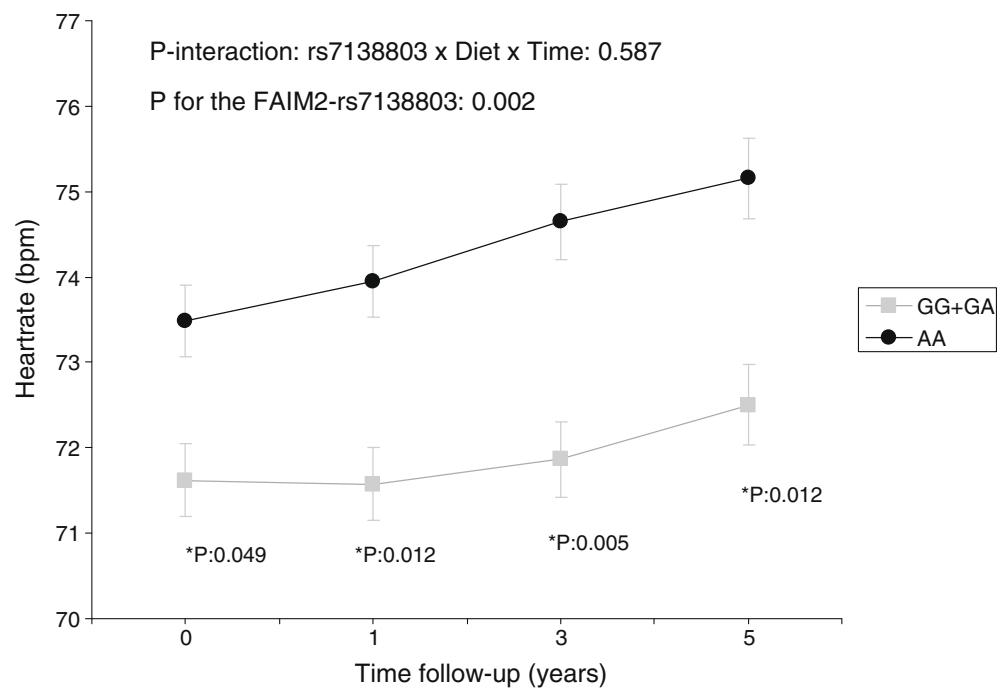

Figure 1 Longitudinal effect of the FAIM2-rs7138803 polymorphism on heart rate in type 2 diabetic subjects. Adjusted means of heart rate in beats per minute (bpm) depending on the polymorphism (GG + GA versus AA) at baseline, 1, 3 and 5-years of follow-up in all type 2 diabetic subjects at baseline having data for all four measurements $(n=1,076)$. Adjusted means were estimated from a repeated-measures ANOVA model with interaction terms adjusted for dietary intervention (MedDiet versus control), sex, age, BMl, medications, smoking, and physical activity. Adjusted $\mathrm{P}$ values for the interaction term among the polymorphism, time, and dietary intervention as well for the overall effect of the polymorphism are shown. *Adjusted P values for the polymorphism at every specific time point. Further adjustment of the model for hypertension at baseline did not change the statistical significance of the results. 
occurred among the 7,161 participants analyzed (30,360 person-years of observation). Of these, 135 were strokes, 100 myocardial infarctions and the others were cardiovascular deaths. Firstly, we longitudinally analyzed the association of the polymorphism with the incidence of cardiovascular events and adjusted the model for dietary intervention (MedDiets and control group). Additional file 1: Table S3 of the Supporting Online Material shows the HRs for total cardiovascular events, stroke and myocardial infarction. In the whole population, we did not observe a significant association between the FAIM2rs7138803 polymorphism (in the recessive model) and myocardial infarction either in the basic model or in the model adjusted for BMI (HR $\mathrm{Hadjusted}_{1}$ 1.57, 95\% CI: 0.962.62). In the analysis stratified by type 2 diabetes, we observed a nominally significant association in type 2 diabetes patients (HR adjusted $_{1.86} ; 95 \%$ CI:1.03-3.37; $\mathrm{P}=0.041$ in AA versus G-carriers). However, this association did not remain statistically significant following correction for multiple comparisons. Figure 2 shows
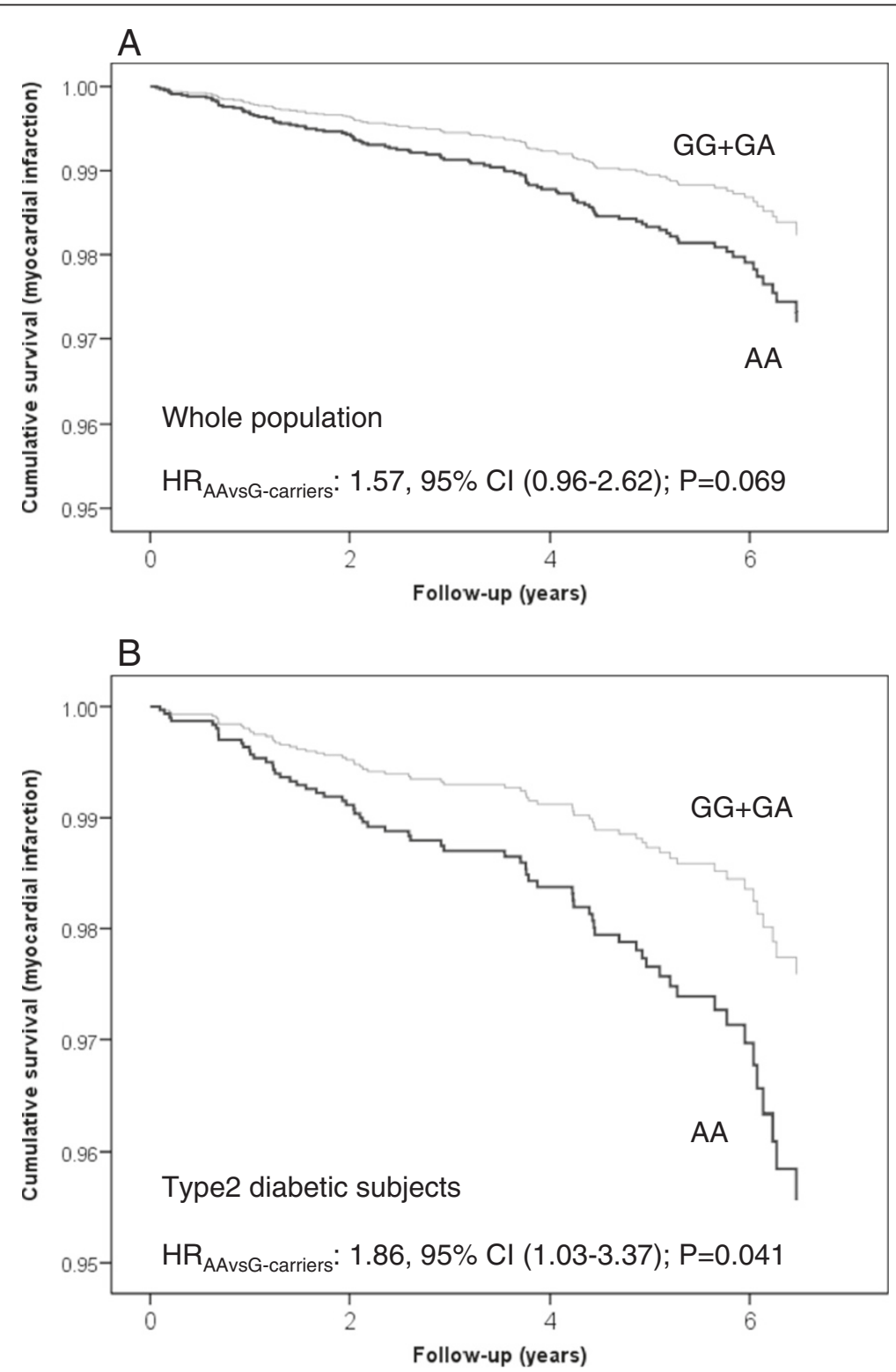

Figure 2 Cumulative myocardial infarction free-survival by the FAIM2-rs7138803 polymorphism in the whole population $(A)(n=7,161)$ and in type 2 diabetic subjects $(\mathbf{B})(\mathbf{n}=\mathbf{3 , 4 6 2}$ ). Cox regression models with outcome of myocardial infarction and the rs7138803 polymorphism (G-allele carriers versus AA) adjusted by dietary intervention group, sex, age, centre, type 2 diabetes, hypertension, medications, BMI, total energy intake, alcohol, smoking and physical activity. The P-values for the FAIM2-rs7138803 polymorphism were obtained from the multivariable adjusted models. 
cumulative myocardial infarction free-survival by the FAIM2-rs7138803 polymorphism in the whole population (A) and in type-2 diabetic subjects (B).

In the study of the modulation by the MedDiet (MedDiet versus control group) of the effects of the FAIM2-rs7138803 polymorphism on the incidence of cardiovascular events, we did not find significant results. None of the interaction terms between MedDiet intervention and the polymorphism reached the nominal statistical significance (not shown). Although, we have sample size limitations to detect gene-diet interaction terms as statistically significant, this lack of significance seems to be derived from homogeneous results. Thus, in the case of myocardial infarction, a similar trend to a greater risk was observed in AA subjects compared with G-carriers both in the control group (HR: 1.66, 95\% CI: $0.70-3.81$ ) as in the MedDiet intervention groups (HR: 1.59; 95\% CI: 0.85-2.99).

\section{Discussion}

In this study on high cardiovascular risk subjects (48\% patients with type 2 diabetes) from a Mediterranean population, we found, as in other studies $[4,6,8,18,20,42]$, that the variant allele of the FAIM2-rs7138803 polymorphism was associated with higher obesity risk. Furthermore, our results support the observations of Paternoster et al. [7] and Sandholt et al. [20] who found that this polymorphism was associated with higher degrees of obesity (BMI $>35)$. Although it is known that the FAIM2 gene codifies an evolutionary conserved inhibitor of Fas-mediated apoptosis [21-23] and the apoptotic pathways are higher in obesity $[43,44]$, the mechanisms by which this association occurs are not known. As we have found for the first time, a strong association between this polymorphism and resting heart rate, as well as with DBP, we can hypothesize on the influence of the FAIM2-rs7138803 polymorphism. Thus, the minor allele may give rise to a variant resulting in less FAIM2 gene expression or activity. Hence minor allele carriers seem to be less protected against apoptosis and appear to present higher levels (despite their magnitude being small) of harmful cardiovascular risk phenotypes (greater obesity, higher DBP and higher resting heart rate), contributing over time increasing the potential risk of myocardial infarction. Although the functions of the FAIM2 in the different metabolic diseases are not well known, it is known that the FAIM2 acts as an antiapoptotic protein which would inhibit Fas-mediated cell death [45]. Moreover a growing body of evidence has shown that Fas-mediated apoptosis is involved in atherosclerosis progression $[25,45,46]$. A study in rats [47] suggested that the augmented expression of apoptotic signalling by the Fas/FasL pathway plays an important role in hypertensive nephrosclerosis. In humans it has also been reported that hypertensive subjects present a greater expression of the FAS gene [48]. In addition, greater serum concentrations of both Fas and FasL have been associated with type- 2 diabetes, hypertension, and cardiovascular disease $[24,33,34,45,49,50]$. In our study, we have described for the first time a statistically significant association between the FAIM2rs7138803 polymorphism and higher DBP, which was independent from BMI and remained significant even after correction for multiple comparisons. Although in a previous study on Chinese subjects [26] the FAIM2rs7138803 polymorphism was associated with higher DBP in children, this association did not remain statistically significant after adjustment for BMI. Moreover, as far as we know, no previous study has reported an association between the FAIM2-rs7138803 polymorphism and heart rate, this association being greater and statistically significant in type 2 diabetic subjects. Moreover, we not only observed this association at baseline but also after analyzing the association of this polymorphism with heart rate longitudinally. The fact that this novel association was found consistently during the 5 years of follow-up in a sub-group of individuals provides greater consistency to this association.

On the other hand, when we studied the modulation of these effects by the MedDiet we did not observe any statistically significant interaction either in the study at baseline or following intervention with MedDiet over 4.8 years follow-up. Future studies are therefore required to better characterize the possible interactions with more specific dietary components. Numerous studies have reported that increased heart rate is a predictor of cardiovascular events and specifically of myocardial infarction [29,51-54]. In our study, we observed that the polymorphism was nominally $(\mathrm{P}<0.041)$ associated with higher risk of myocardial infarction in type 2 diabetes subjects. This would be in line with previous studies that have reported higher apoptosis in type 2 diabetic subjects $[33,34,55]$, greater association between increased heart rate and cardiovascular morbid-mortality in type- 2 diabetes subjects $[29,30,56]$ and with studies showing that apoptosis in cardiomyocytes is a very important risk factor in triggering myocardial infarction $[57,58]$. However, in our study this association did not remain statistically significant after correction for multiple comparisons. This correction is a hotly debated issue in biomedical literature, many authors being opposed to such corrections because of the increase in false negative results. Only one previous study [32], has examined the association between the FAIM2-rs7138803 polymorphism and cardiovascular disease, and no statistical association was found. There are many differences between our study and the Chinese population analyzed and further research is needed into this issue. Another of the polymorphisms associated with obesity in recent GWAs 
(the rs4923461 polymorphism in the BNDF gene) has been associated with higher cardiovascular risk regardless of BMI [59], so providing new evidence of the pleiotropic effects of obesity-related polymorphisms.

\section{Limitations}

Our study has several limitations, one of them being the relatively low number of cardiovascular events (myocardial infarction and stroke) that reduces the statistical power for detecting statistically significant associations between the FAIM2 polymorphism and cardiovascular events as well as to detect gene-diet interactions between the polymorphism and MedDiet intervention in determining cardiovascular events. In line with this observation, we may also have statistical power limitations to detect gene-diet interaction in determining heart rate in the follow-up because only a sub-group of subjects had data at 5-y. At baseline, our sample size consisting of 7,161 subjects was high and allowed us to detect as statistically significant differences in heart rate or DBP around unit. These associations although statistically significant were small in magnitude and may be clinically non-relevant.

\section{Conclusions}

In conclusion, the results of our study confirm the association between the FAIM2-rs7138803 polymorphism and obesity risk, being greater for higher degrees of obesity. Moreover we provide new data on the association between this polymorphism and higher DBP and heart rate regardless of BMI, these associations being higher in subjects with type 2 diabetes. In addition, the association of the polymorphism with heart rate was consistently found over the follow-up, adding more evidence to this novel association. All of this may contribute to the fact that homozygous subjects for the variant allele tended to have a higher risk of myocardial infarction than the other genotypes in type 2 diabetic subjects. This association, although nominally significant did not pass the correction for multiple comparisons and needs to be replicated in further studies.

\section{Additional file}

Additional file 1: Figure S1. Flow-chart of the trial. Figure S2. Interaction between the FAIM2-rs7138803 polymorphism and adherence to the MedDiet in determining BMI (A) and heart rate (B). Figure S3. Stratified analysis of the association between the FAIM2-rs7138803 and diastolic blood pressure (DBP) (A) and heart rate (B) depending on hypertension. Table S1. Demographic, lifestyle, clinical and biochemical characteristics of the participants depending on the FAIM2-rs7138803 polymorphism. Table S2. Association between the FAIM2-rs7138803 polymorphism and categories of obesity. Prevalence and odds ratios (OR). Unadjusted and adjusted models. Table S3. Association between the FAIM2-rs7138803 polymorphism and incidence of cardiovascular diseases in the whole population and by type 2 diabetes status. Hazard ratios (HR) and 95\% confidence intervals (Cl).

\section{Competing interests}

ER is a non paid member of the Scientific Advisory Committee of the California Walnut Commission, Sacramento, CA. The other authors have no competing interest affecting the conduct or reporting of the work submitted.

\section{Authors' contributions}

DC, RE, JMO, JVS, MAMG, ER, JL and LSM designed research; COA, JVS, JIG, $M A M G, E G G, M B, M F, O C, E R, R E, F A, C S, E V$, and $L S M$ conducted research; JVS, MAMG, MB, MF, RE, FA, JL, LSM, EGG, MF, AM, VRG, XP, and EV provided essential materials; DC, COA, JVS, OC and JMO analyzed data and performed statistical analysis; DC, JVS, and JMO wrote paper; DC and JVS had primary responsibility for final content. All authors made substantial contributions to conception and design, acquisition of data or analysis and interpretation of data, drafting the article or revising it critically for important intellectual content and approved the final version of the manuscript.

\section{Acknowledgments}

We thank the participants for their enthusiastic collaboration, the PREDIMED personnel for excellent assistance, and the personnel of all affiliated primary care centers. The funding sources played no role in the experimental design, the collection, analysis or interpretation of data, the writing of the report or the decision to submit the paper for publication.

This study has been supported by The Spanish Ministry of Health (Instituto de Salud Carlos III) and the Ministry of Economy and Innovation, Spain and Fondo Europeo de Desarrollo Regional (projects PI051839, PI070240, PI1001407, G03/140, CIBER 06/03, RD06/0045 PI07-0954, CNIC-06, PI11/02505, SAF2009-12304 and AGL2010-22319-C03-03), by contracts 53-K06-5-10 and 58-1950-9-001 from the US Department of Agriculture Research, USA and by the Generalitat Valenciana, Spain (AP111/10, AP-042/11, BEST11-263, BEST/ 2011/261, GVACOMP2011-151, ACOMP/2011/145 and ACOMP/2012/190).

\section{Author details}

${ }^{1}$ Department of Preventive Medicine and Public Health, School of Medicine, University of Valencia, Valencia, Spain. ${ }^{2}$ CIBER Fisiopatología de la Obesidad y Nutrición, Instituto de Salud Carlos III, Madrid, Spain. ${ }^{3}$ Cardiovascula Risk and Nutrition Research Group, Institut Hospital del Mar d'Investigacions Mèdiques (IMIM), Barcelona, Spain. ${ }^{4}$ Human Nutrition Unit, Faculty of Medicine, IISPV, University Rovira i Virgili, Reus, Spain. ${ }^{5}$ Department of Preventive Medicine and Public Health, School of Medicine, University of Navarra, Pamplona, Spain. ${ }^{6}$ Lipid Clinic, Endocrinology and Nutrition Service, Institut d'Investigacions Biomèdiques August Pi Sunyer (IDIBAPS), Hospital Clinic, Barcelona, Spain. Department of Cardiology, Araba University Hospital, Vitoria, Spain. ${ }^{8}$ Department of Family Medicine, Primary Care Division of Sevilla, San Pablo Health Center, Sevilla, Spain. ${ }^{9}$ Department of Epidemiology, School of Medicine, University of Malaga, Malaga, Spain. ${ }^{10}$ Department of Clinical Sciences, University of Las Palmas de Gran Canaria, Las Palmas de Gran Canaria, Spain. ${ }^{11}$ Instituto de la Grasa, Consejo Superior de Investigaciones Científicas, Sevilla, Spain. ${ }^{12}$ University Institute for Health Sciences Investigation, Hospital Son Dureta, Palma de Mallorca, Spain. ${ }^{13}$ Department of Computer Languages and Systems, School of Technology and Experimental Sciences, Jaume I University, Castellón, Spain. ${ }^{14}$ Primary Care Division, Catalan Institute of Health, Barcelona, Spain. ${ }^{15}$ Lipids and Vascular Risk Unit, Internal Medicine, Hospital Universitario de Bellvitge, Hospitalet de Llobregat, Barcelona, Spain. ${ }^{16}$ Department of Nutrition and Physiology, Faculty of Pharmacy, University of Navarra, Pamplona, Spain. ${ }^{17}$ Department of Cardiovascular Epidemiology and Population Genetics, Centro Nacional de Investigaciones Cardiovasculares (CNIC), Madrid, Spain.

${ }^{18}$ IMDEA Alimentación, Madrid, Spain. ${ }^{19}$ Nutrition and Genomics Laboratory, JM-USDA Human Nutrition Research Center on Aging, Tufts University, Boston, MA, USA. ${ }^{20}$ Department of Internal Medicine, Hospital Clinic, IDIBAPS, Barcelona, Spain. ${ }^{21}$ Genetic and Molecular Epidemiology Unit, Valencia University, Blasco Ibañez, 15, 46010 Valencia, Spain.

Received: 19 November 2013 Accepted: 31 December 2013 Published: 6 January 2014

\section{References}

1. Frayling TM, Timpson NJ, Weedon MN, Zeggini E, Freathy RM, Lindgren CM, Perry JR, Elliott KS, Lango H, Rayner NW, Shields B, Harries LW, Barrett JC, Ellard S, Groves CJ, Knight B, Patch AM, Ness AR, Ebrahim S, Lawlor DA, Ring 
SM, Ben-Shlomo Y, Jarvelin MR, Sovio U, Bennett AJ, Melzer D, Ferrucci L, Loos RJ, Barroso I, Wareham NJ, et al: A common variant in the FTO gene is associated with body mass index and predisposes to childhood and adult obesity. Science 2007, 316:889-894.

2. Loos RJ, Lindgren CM, Li S, Wheeler E, Zhao JH, Prokopenko I, Inouye M, Freathy RM, Attwood AP, Beckmann JS, Berndt SI, Prostate, Lung, Colorectal, and Ovarian (PLCO) Cancer Screening Trial, Jacobs KB, Chanock SJ, Hayes RB, Bergmann S, Bennett AJ, Bingham SA, Bochud M, Brown M, Cauchi S, Connell JM, Cooper C, Smith GD, Day I, Dina C, De S, Dermitzakis ET, Doney AS, et al: Common variants near MC4R are associated with fat mass, weight and risk of obesity. Nat Genet 2008, 40:768-775.

3. Willer CJ, Speliotes EK, Loos RJ, Li S, Lindgren CM, Heid IM, Berndt SI, Elliott AL, Jackson AU, Lamina C, Lettre G, Lim N, Lyon HN, McCarroll SA, Papadakis K, Qi L, Randall JC, Roccasecca RM, Sanna S, Scheet P, Weedon MN, Wheeler E, Zhao JH, Jacobs LC, et al: Six new loci associated with body mass index highlight a neuronal influence on body weight regulation. Nat Genet 2009, 41:25-34.

4. Thorleifsson G, Walters GB, Gudbjartsson DF, Steinthorsdottir V, Sulem P, Helgadottir A, Styrkarsdottir U, Gretarsdottir S, Thorlacius S, Jonsdottir I, Jonsdottir T, Olafsdottir EJ, Olafsdottir GH, Jonsson T, Jonsson F, Borch-Johnsen K, Hansen T, Andersen G, Jorgensen T, Lauritzen T, Aben KK, Verbeek AL, Roeleveld N, Kampman E, Yanek LR, Becker LC, Tryggvadottir L, Rafnar T, Becker DM, Gulcher J, Kiemeney LA, Pedersen O, Kong A, et al: Genome-wide association yields new sequence variants at seven loci that associate with measures of obesity. Nat Genet 2009, 41:18-24.

5. Berndt SI, Gustafsson S, Mägi R, Ganna A, Wheeler E, Feitosa MF, Justice AE, Monda KL, Croteau-Chonka DC, Day FR, Esko T, Fall T, Ferreira T, Gentilini D, Jackson AU, Luan J, Randall JC, Vedantam S, Willer CJ, Winkler TW, Wood AR, Workalemahu T, Hu YJ, Lee SH, Liang L, Lin DY, Min JL, Neale BM, Thorleifsson G, Yang J, Albrecht E, Amin N, et al: Genome-wide meta-analysis identifies 11 new loci for anthropometric traits and provides insights into genetic architecture. Nat Genet 2013, 45:501-512.

6. Speliotes EK, Willer CJ, Berndt SI, Monda KL, Thorleifsson G, Jackson AU, Lango Allen $\mathrm{H}$, Lindgren CM, Luan J, Mägi R, Randall JC, Vedantam S, Winkler TW, Qi L, Workalemahu T, Heid IM, Steinthorsdottir V, Stringham HM, Weedon MN, Wheeler E, Wood AR, Ferreira T, Weyant RJ, Segrè AV, Estrada K, Liang L, Nemesh J, Park JH, Gustafsson S, Kilpeläinen TO, Yang J, Bouatia-Naji N, Esko T, Feitosa MF, Kutalik Z, Mangino M, Raychaudhuri S, Scherag A, Smith AV, Welch R, Zhao JH, Aben KK, Absher DM, Amin N, Dixon AL, Fisher E, et al: Association analyses of 249,796 individuals reveal 18 new loci associated with body mass index. Nat Genet 2010, 42:937-948.

7. Paternoster L, Evans DM, Nohr EA, Holst C, Gaborieau V, Brennan P, Gjesing AP, Grarup N, Witte DR, Jørgensen T, Linneberg A, Lauritzen T, Sandbaek A, Hansen T, Pedersen O, Elliott KS, Kemp JP, St Pourcain B, McMahon G, Zelenika D, Hager J, Lathrop M, Timpson NJ, Smith GD, Sørensen TI: Genome-wide population-based association study of extremely overweight young adults-the GOYA study. PLoS One 2011, 6:e24303.

8. Emerging Risk Factors Collaboration, Sarwar N, Gao P, Seshasai SR, Gobin R, Kaptoge S, Di Angelantonio E, Ingelsson E, Lawlor DA, Selvin E, Stampfer M Stehouwer CD, Lewington S, Pennells L, Thompson A, Sattar N, White IR, Ray KK, Danesh J: Diabetes mellitus, fasting blood glucose concentration, and risk of vascular disease: a collaborative meta-analysis of 102 prospective studies. Lancet 2010, 375:2215-2222.

9. Joshy G, Korda RJ, Attia J, Liu B, Bauman AE, Banks E: Body mass index and incident hospitalisation for cardiovascular disease in 158546 participants from the 45 and Up Study. Int J Obes (Lond) 2013. doi:10.1038/ijo.2013.192.

10. Fall T, Ingelsson E: Genome-wide association studies of obesity and metabolic syndrome. Mol Cell Endocrinol 2012. doi:10.1016/j.mce.2012.08.018.

11. Hotta K, Kitamoto T, Kitamoto A, Mizusawa S, Matsuo T, Nakata Y, Kamohara S, Miyatake N, Kotani K, Komatsu R, Itoh N, Mineo I, Wada J, Yoneda M, Nakajima A, Funahashi T, Miyazaki S, Tokunaga K, Masuzaki H, Ueno T, Hamaguchi K, Tanaka K, Yamada K, Hanafusa T, Oikawa S, Yoshimatsu H, Sakata T, Matsuzawa Y, Nakao $K$, Sekine: Association of variations in the FTO, SCG3 and MTMR9 genes with metabolic syndrome in a Japanese population. J Hum Genet 2011, 56:647-651.

12. Perez-Martinez P, Garcia-Rios A, Delgado-Lista J, Delgado-Casado N, Malagon MM, Marin C, Gomez-Luna P, Caballero J, Perez-Jimenez F, Lopez-Miranda J: A variant near the melanocortin-4 receptor gene regulates postprandial lipid metabolism in a healthy Caucasian population. Br J Nutr 2011, 106:468-471.

13. Wu C, Gong Y, Yuan J, Gong H, Zou Y, Ge J: Identification of shared genetic susceptibility locus for coronary artery disease, type 2 diabetes and obesity: a meta-analysis of genome-wide studies. Cardiovasc Diabetol 2012, 11:68.
14. Hotta K, Nakamura M, Nakamura T, Matsuo T, Nakata Y, Kamohara S, Miyatake N, Kotani K, Komatsu R, Itoh N, Mineo I, Wada J, Masuzaki H, Yoneda M, Nakajima A, Funahashi T, Miyazaki S, Tokunaga K, Kawamoto M, Ueno T, Hamaguchi K, Tanaka K, Yamada K, Hanafusa T, Oikawa S, Yoshimatsu H, Nakao K, Sakata T, Matsuzawa Y, Kamatani N, Nakamura Y: Association between obesity and polymorphisms in SEC16B, TMEM18, GNPDA2, BDNF, FAIM2 and MC4R in a Japanese population. J Hum Genet 2009, 54:727-731.

15. Xi B, Cheng H, Shen Y, Chandak GR, Zhao X, Hou D, Wu L, Wang X, Mi J: Study of 11 BMl-associated loci identified in GWAS for associations with central obesity in the Chinese children. PLoS One 2013, 8:e56472.

16. Hong KW, Oh B: Recapitulation of genome-wide association studies on body mass index in the Korean population. Int J Obes (Lond) 2012, 36:1127-1130.

17. Ntalla I, Panoutsopoulou K, Vlachou P, Southam L, William Rayner N, Zeggini E, Dedoussis GV: Replication of established common genetic variants for adult BMI and childhood obesity in Greek adolescents: the TEENAGE study. Ann Hum Genet 2013, 77:268-274.

18. Mei H, Chen W, Jiang F, He J, Srinivasan S, Smith EN, Schork N, Murray S, Berenson GS: Longitudinal replication studies of GWAS risk SNPS influencing body mass index over the course of childhood and adulthood. PLoS One 2012, 7:e31470.

19. Jääskeläinen T, Paananen J, Lindström J, Eriksson JG, Tuomilehto J, Uusitupa $\mathrm{M}$ : Genetic predisposition to obesity and lifestyle factors - the combined analyses of twenty-six known BMI- and fourteen known waist:hip ratio (WHR)-associated variants in the Finnish Diabetes Prevention Study. M. Br J Nutr 2013, 14:1-10. In press.

20. Sandholt $\mathrm{CH}$, Vestmar MA, Bille DS, Borglykke A, Almind K, Hansen L, Sandbæk A, Lauritzen T, Witte D, Jørgensen T, Pedersen O, Hansen T: Studies of metabolic phenotypic correlates of 15 obesity associated gene variants. PLoS One 2011, 6:e23531

21. Fernández M, Segura MF, Solé C, Colino A, Comella JX, Ceña V: Lifeguard/ neuronal membrane protein 35 regulates Fas ligand-mediated apoptosis in neurons via microdomain recruitment. J Neurochem 2007, 103:190-203.

22. Besirli CG, Zheng QD, Reed DM, Zacks DN: ERK-mediated activation of Fas apoptotic inhibitory molecule 2 (Faim2) prevents apoptosis of $661 \mathrm{~W}$ cells in a model of detachment-induced photoreceptor cell death. PLoS One 2012, 7:e46664.

23. Krammer PH: CD95's deadly mission in the immune system. Nature 2000, 407:789-795.

24. Sahinarslan A, Boyaci B, Kocaman SA, Topal S, Ercin U, Okyay K, Bukan N, Yalçin R, Cengel A: The Relationship of Serum Soluble Fas Ligand (sFasL) Level with the Extent of Coronary Artery Disease. Int J Angiol 2012, 21:29-34.

25. Hanasaki H, Takemura Y, Fukuo K, Ohishi M, Onishi M, Yasuda O, Katsuya T, Awata N, Kato N, Ogihara T, Rakugi H: Fas promoter region gene polymorphism is associated with an increased risk for myocardial infarction. Hypertens Res 2009, 32:261-264.

26. Xi B, Zhao X, Shen Y, Wu L, Hotta K, Hou D, Cheng H, Wang X, Mi J: Associations of obesity susceptibility loci with hypertension in Chinese children. Int J Obes (Lond) 2013, 37:926-930.

27. Custodis F, Reil JC, Laufs U, Böhm M: Heart rate: a global target for cardiovascular disease and therapy along the cardiovascular disease continuum. J Cardio/ 2013, 62:183-187.

28. Palatini P: Heart rate and the cardiometabolic risk. Curr Hypertens Rep 2013, 15:253-259.

29. Palatini P: Heart rate as an independent risk factor for cardiovascular disease: current evidence and basic mechanisms. Drugs 2007, 67(Suppl 2):3-13.

30. Hillis GS, Woodward M, Rodgers A, Chow CK, Li Q, Zoungas S, Patel A, Webster R, Batty GD, Ninomiya T, Mancia G, Poulter NR, Chalmers J: Resting heart rate and the risk of death and cardiovascular complications in patients with type 2 diabetes mellitus. Diabetologia 2012, 55:1283-1290.

31. Reich A, Spering C, Gertz K, Harms C, Gerhardt E, Kronenberg G, Nave KA, Schwab M, Tauber SC, Drinkut A, Harms K, Beier CP, Voigt A, Göbbels S, Endres $M$, Schulz JB: Fas/CD95 regulatory protein Faim2 is neuroprotective after transient brain ischemia. J Neurosci 2011, 31:225-233.

32. Huang H, Zeng Z, Zhang L, Liu R, Li X, Qiang O, Chen Y: Implication of genetic variants near TMEM18, BCDIN3D/FAIM2, and MC4R with coronary artery disease and obesity in Chinese: a angiography-based study. Mol Biol Rep 2012, 39:1739-1744.

33. Tamakoshi A, Suzuki K, Lin Y, Ito Y, Yagyu K, Kikuchi S, Watanabe Y, Inaba Y, Tajima K, Nakachi K, JACC Study Group: Relationship of sFas with metabolic risk factors and their clusters. Eur J Clin Invest 2010, 40:527-533. 
34. Chang J, Zhang G, Zhang L, Hou YP, Liu XL, Zhang L: High admission glucose levels increase Fas apoptosis and mortality in patients with acute ST-elevation myocardial infarction: a prospective cohort study. Cardiovasc Diabetol 2013, 12:171.

35. Boender AJ, van Rozen AJ, Adan RA: Nutritional state affects the expression of the obesity-associated genes Etv5, Faim2, Fto, and Negr1. Obesity (Silver Spring) 2012, 20:2420-2425.

36. Estruch R, Ros E, Salas-Salvadó J, Covas Ml, Corella D, Arós F, Gómez-Gracia E, Ruiz-Gutiérrez V, Fiol M, Lapetra J, Lamuela-Raventos RM, Serra-Majem L, Pintó X, Basora J, Muñoz MA, Sorlí JV, Martínez JA, Martínez-González MA, PREDIMED Study Investigators: Primary prevention of cardiovascular disease with a Mediterranean diet. N Engl J Med 2013, 368:1279-1290.

37. Estruch R, Martínez-González MA, Corella D, Salas-Salvadó J, Ruiz-Gutiérrez V, Covas MI, Fiol M, Gómez-Gracia E, López-Sabater MC, Vinyoles E, Arós F, Conde M, Lahoz C, Lapetra J, Sáez G, Ros E, PREDIMED Study Investigators: Effects of a Mediterranean-style diet on cardiovascular risk factors: a randomized trial. Ann Intern Med 2006, 145:1-11.

38. Martínez-González MÁ, Corella D, Salas-Salvadó J, Ros E, Covas MI, Fiol M, Wärnberg J, Arós F, Ruíz-Gutiérrez V, Lamuela-Raventós RM, Lapetra J, Muñoz MÁ, Martínez JA, Sáez G, Serra-Majem L, Pintó X, Mitjavila MT, Tur JA, Portillo MP, Estruch R, PREDIMED Study Investigators: Cohort Profile: design and methods of the PREDIMED study. Int J Epidemiol 2012, 41:377-385.

39. American Diabetes Association: Diagnosis and classification of diabetes mellitus. Diabetes Care 2008, 31:S55-S60.

40. Fernández-Ballart JD, Piñol JL, Zazpe I, Corella D, Carrasco P, Toledo E, Perez-Bauer M, Martínez-González MA, Salas-Salvadó J, Martín-Moreno JM: Relative validity of a semi-quantitative food-frequency questionnaire in an elderly Mediterranean population of Spain. Br J Nutr 2010, 103:1808-1816.

41. Schröder H, Fitó M, Estruch R, Martínez-González MA, Corella D, SalasSalvadó J, Lamuela-Raventós R, Ros E, Salaverría I, Fiol M, Lapetra J, Vinyoles E, Gómez-Gracia E, Lahoz C, Serra-Majem L, Pintó X, Ruiz-Gutierrez V, Covas Ml: A short screener is valid for assessing Mediterranean diet adherence among older Spanish men and women. J Nutr 2011, 141:1140-1145.

42. Li S, Zhao JH, Luan J, Luben RN, Rodwell SA, Khaw KT, Ong KK, Wareham NJ, Loos RJ: Cumulative effects and predictive value of common obesitysusceptibility variants identified by genome-wide association studies. Am J Clin Nutr 2010, 91:184-190.

43. Herold C, Rennekampff HO, Engeli S: Apoptotic pathways in adipose tissue. Apoptosis 2013, 18:911-916.

44. Pintus F, Floris G, Rufini A: Nutrient availability links mitochondria, apoptosis, and obesity. Aging (Albany NY) 2012, 4:734-741.

45. Ankersmit HJ, Weber T, Auer J, Roth G, Brunner M, Kvas E, Moser B, Spreitzer S, Lassnig E, Maurer E, Hartl P, Wolner E, Boltz-Nitulescu G, Eber B: Increased serum concentrations of soluble CD95/Fas and caspase 1/ICE in patients with acute angina. Heart 2004, 90:151-154.

46. Hoke M, Schillinger M, Zorn G, Wonnerth A, Amighi J, Mlekusch W, Speidl W, Maurer G, Koppensteiner R, Minar E, Wojta J, Niessner A: The prognostic impact of soluble apoptosis-stimulating fragment on mortality in patients with carotid atherosclerosis. Stroke 2011, 42:2465-2470.

47. Sanders PW, Wang PX: Activation of the Fas/Fas ligand pathway in hypertensive renal disease in Dahl/Rapp rats. BMC Nephrol 2002, 3:1.

48. Stoynev N, Dimova I, Rukova B, Hadjidekova S, Nikolova D, Toncheva D, Tankova T: Gene expression in peripheral blood of patients with hypertension and patients with type 2 diabetes. J Cardiovasc Med (Hagerstown) 2013. In press (PMID: 23337395).

49. Tamakoshi A, Suzuki K, Lin Y, Ito Y, Yagyu K, Kikuchi S, Watanabe $Y$, Inaba $Y$, Tajima K, Nakachi K, JACC Study Group: Relationship of soluble fas with body mass index in healthy Japanese adults. Asian PaC J Cancer Prev 2009, 10(Suppl):41-44

50. Troyanov S, Hébert MJ, Masse M, Vigneault N, Sirois I, Madore F: Soluble Fas: a novel predictor of atherosclerosis in dialysis patients. Am J Kidney Dis 2003, 41:1043-1051.

51. Greenland P, Daviglus ML, Dyer AR, Liu K, Huang CF, Goldberger JJ, Stamler $\mathrm{J}$ : Resting heart rate is a risk factor for cardiovascular and noncardiovascular mortality: the Chicago Heart Association Detection Project in Industry. Am J Epidemiol 1999, 1(149):853-862.

52. Jensen MT, Marott $J$, Allin KH, Nordestgaard BG, Jensen GB: Resting heart rate is associated with cardiovascular and all-cause mortality after adjusting for inflammatory markers: the Copenhagen City Heart Study. Eur J Prev Cardiol 2012, 19:102-108.
53. Jensen MT, Suadicani P, Hein HO, Gyntelberg F: Elevated resting heart rate, physical fitness and all-cause mortality: a 16-year follow-up in the Copenhagen Male Study. Heart 2013, 99:882-887.

54. Fox K, Bousser MG, Amarenco P, Chamorro A, Fisher M, Ford I, Hennerici MG, Mattle HP, Rothwell PM, PERFORM Study Investigators: Heart rate is a prognostic risk factor for myocardial infarction: a post hoc analysis in the PERFORM (Prevention of cerebrovascular and cardiovascular Events of ischemic origin with terutroban in patients with a history of ischemic stroke or transient ischemic attack) study population. Int J Cardio/ 2013, 168:3500-3505.

55. Nogueira TC, Paula FM, Villate O, Colli ML, Moura RF, Cunha DA, Marselli L, Marchetti P, Cnop M, Julier C, Eizirik DL: GLIS3, A susceptibility gene for type 1 and type 2 diabetes, modulates pancreatic beta cell apoptosis via regulation of a splice variant of the BH3-only protein Bim. PLOS Genet 2013, 9:e1003532.

56. Chavali V, Tyagi SC, Mishra PK: Predictors and prevention of diabetic cardiomyopathy. Diabetes Metab Syndr Obes 2013, 6:151-160.

57. Orogo AM, Gustafsson AB: Cell death in the myocardium: my heart won't go on. IUBMB Life 2013, 65:651-656.

58. Gerczuk PZ, Breckenridge DG, Liles JT, Budas GR, Shryock JC, Belardinell L, Kloner RA, Dai W: An apoptosis signal-regulating kinase 1 inhibitor reduces cardiomyocyte apoptosis and infarct size in a rat ischemiareperfusion model. J Cardiovasc Pharmacol 2012, 60:276-282.

59. Halldén S, Sjögren M, Hedblad B, Engström G, Narkiewicz K, Hoffmann M, Wahlstrand B, Hedner T, Melander O: Smoking and obesity associated BDNF gene variance predicts total and cardiovascular mortality in smokers. Heart 2013, 99:949-953.

doi:10.1186/1475-2840-13-5

Cite this article as: Corella et al:: Novel association of the obesity riskallele near Fas Apoptotic Inhibitory Molecule 2 (FAIM2) gene with heart rate and study of its effects on myocardial infarction in diabetic participants of the PREDIMED trial. Cardiovascular Diabetology 2014 13:5

\section{Submit your next manuscript to BioMed Central and take full advantage of:}

- Convenient online submission

- Thorough peer review

- No space constraints or color figure charges

- Immediate publication on acceptance

- Inclusion in PubMed, CAS, Scopus and Google Scholar

- Research which is freely available for redistribution 